0.71 , inter-observer mean of 8.64 and within-patient standard deviation (SD) of 4.25. For the second group of assessors who returned 2 days after training $(n=14)$, compared to the experts' scores, the inter-observer and intra-observer variability was 0.73 and 0.85 respectively. The inter-observer mean was 7.39 with a within-patient SD of 3.65. The intra-observer mean was 6.92 and within-patient SD was 2.73.

Conclusions: There was substantial inter-observer reliability and excellent intraobserver reliability. This is the first study examining the training of assessors using the SCTC training guidelines and our results support the importance of standardised teaching for mRSS.

Disclosure of Interest: None declared

DOI: 10.1136/annrheumdis-2018-eular.4384

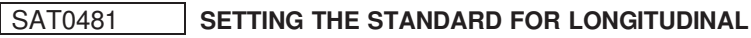 FOLLOW-UP OF SYSTEMIC SCLEROSIS; A EUSTAR DELPHI-BASED EXPERT CONSENSUS}

A.-M. Hoffmann-Vold ${ }^{1}$, O. Distler ${ }^{2}$, M. Baron ${ }^{3}$, O. Kowal-Bielecka ${ }^{4}$, D. Khanna ${ }^{5}$, Y. Allanore ${ }^{6}$ on behalf of EUSTAR, SCTC. ${ }^{1}$ Oslo University Hospital, Oslo, Norway, ${ }^{2}$ University Hospital Zurich, Zurich, Switzerland; ${ }^{3}$ Jewish General Hospital, Montreal, Canada; ${ }^{4}$ Medical University of Bialystok, Bialystok, Poland; ${ }^{5}$ University of Michigan, Ann Arbor, USA; ${ }^{6}$ Cochin Hospital, Paris, France

Background: Systemic sclerosis (SSc) is a severe multi-organ disease associated with substantial morbidity and mortality. Lung and heart involvement are currently the major causes of disease-related deaths. Skin, gastrointestinal and musculoskeletal involvement, digital ulcers and Raynaud's phenomenon have shown to be associated with high morbidity, reduced quality of life and lower social functioning. SSc is progressive and many of the disease features aggravate over time, while other features may commence during the disease course. However, to date, there are no established standardised international guidelines for follow-up of SSc patients.

Objectives: The aim was to establish an expert consensus regarding the longitudinal systemic assessment of organ involvement in SSc to improve the standardof-care for SSc patients.

Methods: All experts in SSc from the European Scleroderma Trials and Research Group (EUSTAR) network and the scleroderma clinical trial consortium (SCTC) were invited to participate. The final expert panel consisted of a multidisciplinary team including rheumatologists, dermatologists, pulmonologists, cardiologists and nephrologists. The Delphi method was Internet based and completed from December 2016 until October 2017. The method entailed the entire group of experts who anonymously replied to in total 5 online questionnaires. The experts were asked to score each item in the survey to answer the following question: "Which domains and tools do you strongly suggest for the minimum annual systemic investigation of SSc patients". Every item in every questionnaire was asked to be rated between $0 \%$ and $100 \%$, with $100 \%$ as 'very important/appropriate' and $0 \%$ as 'not important/appropriate at all'. Parameters rated $>80 \%$ by more than $80 \%$ of the experts were rated as acceptable in all steps.

Results: Of the 269 invited centres, physicians from $132(49.1 \%)$ centres participated in the DELPHI survey of 5 steps. Of the included participants, $71.3 \%$ were seeing $>50$ SSc patients annually and $48.3 \%$ of the centres seeing $>100$ patients on an annual basis. Of all, 98 of the centres were located in Europe $(74.2 \%), 18$ in North America (13.6\%), 7 in Asia (5.3\%), 5 in South America (3.8\%) and 4 in Oceania $(3.0 \%)$. In the first round, 23 domains were suggested by the expert panel. After the second Delphi step, 10 domains were included (figure 1). In the third round, tools for each domain were received. The tools were included in the fourth step and rated by all participating experts. The tools for each of the 10 domains that were rated appropriately by all experts were included in the last step of the DELPHI survey and were re-rated. The final tools for each domain are shown in figure 1 and can be seen as the collective opinions of the convened expert panel.

Abstract SAT0481 - Table 1. Overview of the tools for each domain

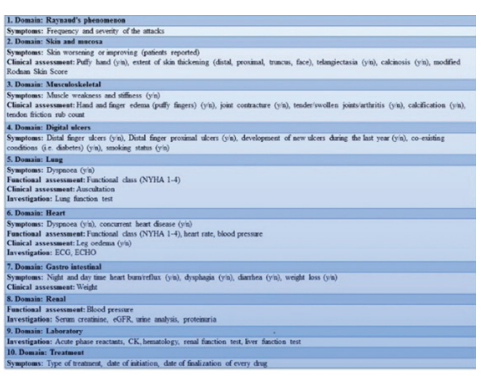

Conclusions: Through five Delphi rounds with world leading experts in SSc, an expert consensus was established on strongly suggested tools for a minimum longitudinal systemic assessment of organ involvement in SSc to improve the standard-of-care for patients with SSc.

Disclosure of Interest: None declared

DOI: 10.1136/annrheumdis-2018-eular.4891

\section{SAT0482 UNDIFFERENTIATED CONNECTIVE TISSUE DISEASE AT RISK FOR SYSTEMIC SCLEROSIS: PREDICTIVE ROLE OF ANTI-TOPOISOMERASE AND AVASCULAR AREAS}

A. Riccardi, V. Messiniti, S. Fasano, G. Valentini. Rheumatology Unit, University of Campania "Luigi Vanvitelli", Naples, Italy

Background: Undifferentiated connective tissue disease at risk for systemic sclerosis (UCTD-risk-SSc) is a condition characterised by Raynaud's phenom enon and either SSc marker autoantibodies or typical capillaroscopic findings or both, unsatisfying classification criteria for $\mathrm{SSc}^{1}$ and reported to evolve into definite SSc in about $50 \%$ of 60 cases over a 12-102 months follow-up time. ${ }^{2}$ We found marker autoantibody positivity to predict the evolution into SSc satisfying 2013 ACR criteria for the disease. ${ }^{3}$

Objectives: To investigate in patients followed-up for a longer time if distinct marker autoantibody specificities have a different predictive value.

Methods: Sixty-five patients consecutively admitted to a tertiary Rheumatology Unit from November 1 st 2000 to December 31 st 2016 and diagnosed as UCTDrisk-SSc were enrolled in the study. Patients were monitored for a median of 27 months (range 6-144) and were evaluated twice yearly to assess disease progression. Kaplan-Meier curves and the log-rank test were used to analyse differences in fulfilling the criteria for SSc between subsets. Risk prediction was assessed by univariate Cox regression analysis.

Results: During follow-up 40/53 marker autoantibody-positive patients (75.5\%) versus $3 / 12(25 \%)$ marker autoantibody negative ones satisfied SSc criteria $(\mathrm{p}=0.006)$. Out of them, 11/12 (91.7\%) anti-topoisomerase (Scl70) positive versus $29 / 40(72.5 \%)$ anti-centromere (ACA) positive patients evolved into definite SSc $(\mathrm{p}=0.04)$. In univariate analysis, anti-Scl70 positivity increased by 2 -fold the risk of a definite SSc outcome (HR $2.195 \% \mathrm{Cl} 0.9-4.4)$ with respect to ACA positivity (HR $0.595 \% \mathrm{Cl} 0.2-1.0)(p=0.05)$. In addition $3 / 3(100 \%)$ patients with avascula areas at baseline versus $40 / 62(64.5 \%)$ with megacapillaries only or no capillaroscopic abnormalities satisfied SSc criteria over a 12-38 months follow-up time $(p=0.06)$.

Conclusions: We confirm that autoantibody positivity patients presents a faster evolution. Moreover we first detected an increased HR of Scl-70 versus ACA positivity and a potential role of baseline detected avascular areas.

\section{REFERENCES:}

[1] Valentini G. Undifferentiated Connective Tissue Disease at risk for systemic sclerosis (SSc) (so far referred to as very early/early SSc or preSSc). Autoimmun Rev 2015.

[2] Valentini G, et al. Early Systemic Sclerosis: Analysis of the Disease Course in Patients With Marker Autoantibody and/or Capillaroscopic Positivity. Arthritis Care Res 2014.

[3] van den Hoogen F, et al. 2013 classification criteria for systemic sclerosis: an American college of rheumatology/European league against rheumatism collaborative initiative. Ann Rheum Dis 2013.

Disclosure of Interest: None declared

DOI: 10.1136/annrheumdis-2018-eular.4402

\section{SAT0483 FEMALE SEXUAL DYSFUNCTION IN PATIENTS WITH SYSTEMIC SCLEROSIS}

B. Hermankova ${ }^{1,2}$, M. Spiritovic ${ }^{1,2}$, H. Smucrova ${ }^{1}$, S. Oreska ${ }^{1}$, H. Storkanova ${ }^{1}$, K. Pavelka ${ }^{1}$, J. Vencovsky ${ }^{1}$, L. Senolt ${ }^{1}$, R. Becvar ${ }^{1}$, M. Tomcik ${ }^{1}{ }^{1}$ Department of Rheumatology, 1st Medical Faculty, Charles University, Institute of Rheumatology, ${ }^{2}$ Department of Physiotherapy, Faculty of Physical Education and Sport, Charles University, Prague, Czech Republic

Background: Systemic sclerosis (SSc) is a chronic autoimmune disease leading to various physical and psychological impairments including sexual dysfunction. Objectives: To assess sexual functions/quality of life and pelvic floor function in female SSc patients compared to age-/sex-matched healthy controls $(\mathrm{HC})$, and to analyse the potential impact of disease activity, fatigue, physical activity and depression.

Methods: In total, 41 women with SSc (mean age: 50.9, disease duration: 5.8 years, IcSSc/dcSSc: 18/23, mRSS: 13.6, ESSG activity index: 2.5), who fulfilled the ACR/EULAR 2013 criteria, and 41 healthy controls (mean age: 50.9) without rheumatic diseases filled in 12 well-established and validated questionnaires assessing sexual function/quality of life, pelvic floor function, fatigue, physical 
activity and depression. Full names of questionnaires are listed in the table 1 Data are presented as mean \pm SEM.

Results: Compared to HC, patients with SSc had significantly higher prevalence and greater severity of sexual dysfunction (FSFI, BISF-W: in all subscales as well as total scores), dysfunction of pelvic floor (PISQ-12, PFIQ7), and worse sexual quality of life (SQol-F) (table 1). Worse scores in SSc patients were associated with higher disease activity [ESSG activity index: SQol-F $(r=-0.364, p=0.0443)$, PFIQ7-gynaecological subscale $(r=0.492, p=0.0036)$ ], greater fatigue [all three questionnaires FSS/FIS/MAF correlated negatively with FSFI, BISF-W], more severe depression [BDI-II: FSFI $(r=-0.553, p=0.0002)$, BISF-W $(r=-0.514$, $\mathrm{p}=0.0007)$, PFIQ7 $(\mathrm{r}=0.495, \mathrm{p}=0,0010)]$, deteriorated quality of life [SHAQ: FSFI $(r=-0.536, p=0.0003), \quad B I S F-W \quad(r=-0.563, p=0.0001), \quad S Q o l-F \quad(r=-0.338$, $\mathrm{p}=0.0382)$, PISQ-12 $(\mathrm{r}=0.563, \mathrm{p}=0.0051), \mathrm{PFIQ7}(\mathrm{r}=0.380, \mathrm{p}=0.0142)]$, and worse ability to perform physical activities [HAP: FSFI $(r=0.407, p=0.0082)$, BISF-W $(r=0.409, p=0.0078)]$

\begin{tabular}{|c|c|c|c|}
\hline Questionnaire: score range & $\begin{array}{c}\text { Systemic } \\
\text { sclerosis } \\
(n=41)\end{array}$ & $\begin{array}{c}\text { Healthy } \\
\text { controls } \\
(n=41)\end{array}$ & p-value \\
\hline $\begin{array}{l}\text { FSFI: Female Sexual Function Index: 2(worst)- } \\
36 \text { (best) }\end{array}$ & $15.2 \pm 1.7$ & $25.0 \pm 1.7$ & $\mathrm{p}<0.0001$ \\
\hline $\begin{array}{l}\text { BISF-W: Brief Index of Sexual Function for } \\
\text { Women: }-16 \text { (worst) }-75 \text { (best) }\end{array}$ & $17.5 \pm 2.8$ & $29.7 \pm 2.8$ & $\mathrm{p}=0.0027$ \\
\hline $\begin{array}{l}\text { PISQ-12: Pelvic Organ Prolapse/Urinary } \\
\text { Incontinence Sexual Questionnaire short form: } \\
0 \text { (best)-48(worst) }\end{array}$ & $13.9 \pm 0.9$ & $8.5 \pm 0.7$ & $\mathrm{p}<0.0001$ \\
\hline $\begin{array}{l}\text { PFIQ7: Pelvic Floor Distress Inventory } \\
\text { Questionnaire - short form 7: } \\
\text { 0(best)-300(worst) }\end{array}$ & $26.4 \pm 5.9$ & $7.1 \pm 2.2$ & $\mathrm{p}=0.0092$ \\
\hline $\begin{array}{l}\text { SQoL-F: Sexual Quality of Life Questionnaire - } \\
\text { Female: } 0 \text { (worst) }-100 \text { (best) }\end{array}$ & $56.7 \pm 3.9$ & $78.8 \pm 3.3$ & $\mathrm{p}<0.0001$ \\
\hline FSS: Fatigue Severity Scale: 9(best)-63(worst) & $40.7 \pm 2.2$ & $6.9 \pm 1.0$ & $\mathrm{p}<0.0001$ \\
\hline FIS: Fatigue Impact Scale: 0 (best) -160 (worst) & $59.2 \pm 4.9$ & $28.8 \pm 4.3$ & $\mathrm{p}<0.0001$ \\
\hline $\begin{array}{l}\text { MAF: Multidimensional Assessment of Fatigue } \\
\text { Scale: } 1 \text { (best) }-50 \text { (worst) }\end{array}$ & $26.0 \pm 1.6$ & $13.6 \pm 1.3$ & $\mathrm{p}<0.0001$ \\
\hline $\begin{array}{l}\text { BDI-II: Beck's Depression Inventory II: 0(best)- } \\
63 \text { (worst) }\end{array}$ & $14.2 \pm 1.3$ & $4.8 \pm 0.8$ & $\mathrm{p}<0.0001$ \\
\hline $\begin{array}{l}\text { HAP: Human Activity Profile-adjusted activity } \\
\text { score: } 0 \text { (worst)-94(best) }\end{array}$ & $49.4 \pm 3.7$ & $81.1 \pm 1.5$ & $p<0.0001$ \\
\hline $\begin{array}{l}\text { HAQ: Health Assessment Questionnaire: } 0 \\
\text { (best)-3(worst) }\end{array}$ & $0.9 \pm 0.1$ & $0.1 \pm 0.0$ & $\mathrm{p}<0.0001$ \\
\hline
\end{tabular}

Conclusions: Women with SSc reported significantly impaired sexual function, sexual quality of life and pelvic floor function than age-matched healthy controls. Worse scores in SSc were associated with disease activity, physical activity, fatigue, depression and quality of life.

Acknowledgements: Supported by AZV-16- 33574A and MHCR 023728.

Disclosure of Interest: None declared

DOI: 10.1136/annrheumdis-2018-eular.7454

\section{SAT0484 PERFORMANCE OF THE 2017 EULAR/ACR CLASSIFICATION CRITERIA FOR INFLAMMATORY MYOSITIS AND THEIR MAJOR SUBGROUPS IN THE REMICAM (REGISTRY OF INFLAMMATORY MYOPATHIES IN THE MADRID COMMUNITY)}

E. Rabadán ${ }^{1}$, B.E. Joven ${ }^{1}$, F. Lozano ${ }^{1}$, L. Nuño ${ }^{2}$, F.J. López-Longo ${ }^{3}$, J. MartínezBarrios $^{3}$, C. Larena ${ }^{4}$, M. Blazquez ${ }^{4}$, C. Barbadillo ${ }^{5}$, I. Llorente ${ }^{6}$, A. Pérez ${ }^{7}$, T. Cobo ${ }^{8}$, R. Almodovar ${ }^{9}$, L. Lojo ${ }^{10}$, R. Calvo ${ }^{1}$, M.J. García de Yébenes ${ }^{11}$, P. E. Carreira ${ }^{1}$ on behalf of REMICAM group. ${ }^{1} \mathrm{H} 12$ Octubre; ${ }^{2} \mathrm{H} \mathrm{La} \mathrm{Paz} ;{ }^{3} \mathrm{H}$ Gregorio Marañón; ${ }^{4} \mathrm{H}$ Ramón y Cajal; ${ }^{5} \mathrm{H}$. Puerta de Hierro; ${ }^{6} \mathrm{H}$. La Princesa; ${ }^{7} \mathrm{H}$ Príncipe de Asturias; ${ }^{8} \mathrm{H}$ Infanta Sofía; ${ }^{9} \mathrm{H}$ Fundación Alcorcón; ${ }^{10} \mathrm{H}$ Infanta Leonor, ${ }^{11}$ Instituto musculoesquelético, Madrid, Spain

Background: A collaborative EULAR/ACR Project has developed new criteria for inflammatory myopathies $(\mathrm{IM})$ and their subgoups ${ }^{1}$

Objectives: To analyse agreement between the 2017 IM classification criteria and the Bohan and Peter(BP) criteria in REMICAM cohort ${ }^{2}$

Methods: All patients were included. New criteria were applied to obtain classification as: possible(Pos), probable(Pro) and definitive(Def) IM, and subclassification in 6 subgroups: polymyositis(PM), dermatomyositis(DM), juvenile DM(JDM), amiopathic DM(ADM), inclusion body myositis(IBM) and juvenile myositis(JM). The 7 subgroups in REMICAM were harmonised to fit the 6 subgroups of the 2017 criteria. Agreement between 2017 and BP criteria was analysed in classification/ subclassification, calculating the weighted kappa value (k). Subanalysis including only patients with available data on the muscle strength items required for the 2017 criteria, and in those having also muscle biopsy data, were conducted.

Results: From 479 REMICAM patients, 477 (99.6\%), fulfilled BP criteria $(5.9 \%$ Pos, 26.8\%Pro, 67.4\%Def) and 431 (89.9\%) 2017 criteria (2.5\%Pos, $21.8 \%$ Pro, 65.7 Def). Global agreement between both criteria was $89.5 \%$. Agreement between subtypes (Pos, Pro, Def) was low ( $k=0.15)$. When 399 patients with muscle strength data, and 243 with muscle biopsy data were analysed, results were similar $(k=0.17)$. Disagreement was mainly seen in Pos/Pro subtypes with BP criteria, since $60 \%$ classified as Def when the 2017 criteria were applied. Agreement in the different subgroups of IM (PM, DM, JDM, ADM, IBM, JM) between both criteria was very high $(\mathrm{k}=0.94)$.

Conclusions: The new 2017 EULAR/ACR criteria for IM classification show good agreement with BP criteria in the REMICAM cohort. New criteria classify $60 \%$ of Pos/Pro patients by BP criteria, as Def, and show very high agreement between IM subgroups. Validation studies are needed, but our results in this large cohort suggest the 2017 criteria might be useful for clinical trials and research in IM.

\section{REFERENCES:}

[1] Lundberg IE. Ann Rheum Dis 2017;76:1955-64.

[2] Nuño L. Rheumatol Clin 2017;13:331-7.

Disclosure of Interest: None declared

DOI: 10.1136/annrheumdis-2018-eular.6843

\section{SAT0485 WHAT IS THE EFFECT OF CYCLOPHOSPHAMIDE IV PULSE THERAPY IN PATIENTS WITH DIFFUSE CUTANEOUS SYSTEMIC SCLEROSIS ON SKIN INVOLVEMENT: AN OBSERVATIONAL STUDY}

B. Kersten, N. den Broeder, F. van den Hoogen, E. van den Ende, M. Vonk. Rheumatology, Radboud University Medical Center, Nijmegen, Netherlands

Background: Patients with systemic sclerosis who have proximal skin involvement are classified as diffuse cutaneous systemic sclerosis (DcSSc). Patients with progressive skin involvement have worse prognosis due to internal organ involvement. Treatment options of these patients consist among others of cyclophosphamide iv pulse therapy (iv $\mathrm{CYC}$ ). ${ }^{1}$ Recent studies show significant improvement of skin thickening in patients treated with CYC orally, ${ }^{2}$ but the effect of iv $\mathrm{CYC}$ on skin involvement remains unclear.

Objectives: To examine the extent of skin involvement during 12 monthly iv CYC $\left(750 \mathrm{mg} / \mathrm{m}^{2}\right)$ in DcSSc and to identify factors that predict response to therapy. Methods: Patients with DcSSc receiving iv CYC between 2004 and 2016 were included if they received at least 6 pulses. Skin involvement was accessed with the modified Rodnan Skinscore (mRSS) at baseline, month 6, 12, 24 and 36 by the same trained rheumatologist as part of routine care. Data of patients with the baseline measurement and at least one follow up measurement were included in the study. Missing mRSS data were imputed using multiple imputation by chained equation. Patients were classified as responders if the mRSS decreased at least 5 points and $25 \%$ from baseline at month 12 . A prediction model for response at 12 months was created using backwards logistic regression considering baseline variables and response at 6 months as possible predictors.

Results: A total of 99 patients were included. The mean improvement of mRSS over time was $-4.05(95 \% \mathrm{Cl}-5.53$ to -2.55$)$ (figure 1). $43 \%$ of patients had a response according to the response criteria.

Abstract SAT0485 - Table 1. Demographic and clinical characteristics of responders and non-responders

\begin{tabular}{lcc}
\hline & $\begin{array}{c}\text { Responders at 12 months } \\
(\mathrm{n}=40)\end{array}$ & $\begin{array}{c}\text { Non-responders at } \\
12 \text { months }(\mathrm{n}=51)\end{array}$ \\
\hline Age, mean (sd) & $52(14)$ & $54(13)$ \\
Female gender, $\mathrm{n}(\%)$ & $19(48 \%)$ & $19(37 \%)$ \\
Baseline mRSS, median (IQR) & $13(9-21)$ & $19(15-24)$ \\
Disease duration (months), & $3(1-12)$ & $6(2-18)$ \\
median (IQR) & & $37(73 \%)$ \\
infusions completed, $\mathrm{n}(\%)$ & $37(93 \%)$ & $14(27 \%)$ \\
12 & $3(8 \%)$ & $19(37 \%)$ \\
$\geq 6$ and<12 & $12(30 \%)$ & $29(57 \%)$ \\
Antibodies & $24(60 \%)$ & $1(2 \%)$ \\
-ANA & $17(46 \%)$ & \\
-Anti-topoisomerase & & \\
Response at 6 months & &
\end{tabular}

In univariate prediction models, baseline mRSS (OR 1.06, $\mathrm{p}=0.024)$, response at 6 months (OR: $37.45, p<0.001)$ and completed treatment (yes/no) (OR: 4.108 $\mathrm{p}=0.033$ ), were significant predictors of response at 12 months. For the last variable it should be mentioned that some patients who did not achieve a response at month 6 did not continue iv CYC for that reason. 